\title{
COMPORTAMENTO DE HÍBRIDOS DE MILHO SELECIONADOS E NÃO SELECIONADOS PARAASI SOB ESTRESSE DE ÁGUA NO FLORESCIMENTO E NO ENCHIMENTO DE GRÃOS
}

\author{
MANOEL XAVIER DOS SANTOS ${ }^{1}$, CAMILO DE LELIS TEIXEIRA DE ANDRADE ${ }^{1}$, ANTÔNIO \\ CARLOS DE OLIVEIRA ${ }^{1}$, CARLOS EDUARDO PRADO LEITE ${ }^{1}$, HÉLIO WILSON LEMOS \\ CARVALHO $^{2}$, ELTO EUGÊNIO GOMES E GAMA ${ }^{1}$, CLESO ANTÔNIO PATTO PACHECO ${ }^{1}$, \\ PAULO EVARISTO OLIVEIRA GUMARÃES ${ }^{1}$, SIDNEY NETTO PARENTONI ${ }^{1}$
}

\author{
${ }^{1}$ Pesquisadores Embrapa Milho e Sorgo. Caixa Postal 151, CEP 35701-970 Sete Lagoas, MG. E-mail: \\ xavier@cnpms.embrapa.br (autor paracorrespondência). \\ ${ }^{2}$ Pesquisador Embrapa Tabuleiros Costeiros. Caixa postal 44, CEP 49001-970 Aracaju, SE.
}

Revista Brasileira de Milho e Sorgo, v.2, n.2, p.71-81, 2003

\begin{abstract}
RESUMO - A seca é um dos principais estresses abióticos que reduzem a produção do milho. Essa redução depende do estádio de desenvolvimento da cultura e da duração do período do estresse de água na planta. A sincronia de florescimento masculino e feminino (ASI) tem sido relatada como de fácil medição e correlacionada negativamente com a tolerância a seca. O objetivo deste trabalho foi verificar o comportamento de híbridos originários de linhagens selecionadas e não selecionadas para ASI, sob condições de estresse de água, no período do florescimento/enchimento de grãos. As lâminas de irrigação aplicadas foram medidas em baterias de 16 coletores instalados em cada experimento. No ensaio com estresse, as irrigações foram interrompidas aos 55 dias após o plantio (dap) e reiniciadas aos 90 dap. Para avaliar o nível do estresse hídrico aplicado, monitorou-se a umidade do solo nas camadas de 0 a 20, 20 a 40 e 40 a $60 \mathrm{~cm}$ do perfil do solo, empregando-se o método gravimétrico. Foram utilizados dez híbridos não selecionados para ASI (NSASI), cinco híbridos com 100\% ASI, cinco híbridos com 50\% ASI e duas testemunhas comerciais. Em ambos os ensaios, o delineamento experimental utilizado foi em blocos ao acaso, com três repetições e a parcela foi formada por duas fileiras de $5 \mathrm{~m}$ de comprimento. Foram encontradas diferenças significativas $(\mathrm{P}<0,01)$ para todas as características avaliadas em cada ambiente e para peso de grãos, número de espigas e altura de plantas na análise conjunta. Os híbridos com 100\% ASI mostraram, em média, ASI zero e manifestaram protoginia e os demais apresentaram protandria. Os híbridos NSASI apresentaram redução média de $62 \%$ na produtividade e os híbridos com $100 \%$ ASI e $50 \%$ ASI mostraram reduções médias de $44,8 \%$ e $54 \%$, respectivamente. As produtividades médias mais altas dos híbridos com ASI, na condição de estresse de água, parecem estar mais associadas com o número de espigas do que com a característica ASI.
\end{abstract}

Palavras-chave: sincronia de florescimento masculino e feminino, tolerância à seca.

\section{SELECTED AND NON-SELECTED MAIZE HYBRIDS BEHAVIOR FOR ASI UNDER WATER STRESS IN FLOWERINGAND GRAIN FILLING}

\begin{abstract}
Among abiotic stresses, drought is one of the most serious problem that reduces maize production. This reduction depends on the development of the culture and on the scarcity of water. The Anthesis Silk Interval (ASI) has been related as a trait of easy measurement and it is negatively correlated with drought tolerance. The objective of this work was to verify the
\end{abstract}


hybrids behavior originated from selected and non-selected inbreed lines for ASI under water stress during flowering/grain filling stages. The applied irrigation was measured in collecting cans placed in each experiment. In the experiment with stress the irrigation was interrupted at 55 days after planting date (dap) and initiated again at 90 dap. To evaluate the applied water stress, soil-water was monitored in three depths of the soil profile (0-20, 20-40 and 40-60 $\mathrm{cm}$ ) using the gravimetric method. Ten non-selected hybrids for ASI (NSASI), five hybrids with $100 \%$ ASI, five hybrids with $50 \%$ ASI and two commercial checks were used. For both trials the experimental design was randomized complete blocks with three replications and a plot formed by two five-meter-long rows. Significant differences were found $(\mathrm{P}<0.01)$ for all evaluated traits in each environment and for grain weight, ear number and plant height in the combined analysis. The hybrids with ASI 100\% showed, in average, zero ASI and they showed protogyny while the others showed protandry. The NSASI hybrids showed an average reduction of $62 \%$ in the productivity while hybrids with $100 \%$ ASI and $50 \%$ ASI showed average reductions of $44,8 \%$ and $54 \%$, respectively. The highest average productivity of the ASI hybrids in the environment with moisture stress seems to be more associated with the higher ear number than with the ASI trait.

Key words: anthesis silk interval, drought tolerance.

Em condições de clima tropical, a seca é uma das principais limitações para a produção de milho e a utilização de genótipos tolerantes tem sido apontada como a solução para o aumento da produtividade. Dados estimados por Santos et al. (1997) mostraram que, no Brasil, essas perdas podem variar de $14 \%$ a 28\%; Edmeades et al. (1989) estimaram que $80 \%$ do milho plantado em regiões tropicais apresentou reduções que variaram de 10\% a 50\%. Selecionar sob condições de estresse de água traz sérias dificuldades, incluindo, entre outras, a condução dos ensaios, rigoroso controle ambiental e redução na variância genética (Blum, 1988; Johnson \& Geadelmann, 1989). Essas, talvez, sejam as principais razões dos poucos resultados encontrados na literatura com trabalhos para a tolerância à seca em milho. Tolerância à seca tem sido definida como a habilidade que as plantas têm de produzir sob condições de estresse de água, havendo, todavia, mecanismos que as tornam mais eficientes na produção (Levitt, 1972). Os efeitos adversos da falta de água são mais severos no período do florescimento e a literatura mostra que estresses de um a dois dias nessa fase podem causar uma redução de $22 \%$ na produtividade (Robins \& Domingo, 1953). Em híbridos selecionados para a característica sincronia de florescimento masculino e feminino (ASI) e sob estresse de água considerado moderado, Santos et al. (2000) averiguaram redução média de $35 \%$ na produtividade, podendo ocorrer reduções superiores a 50\%, dependendo da incidência e da duração do estresse (Rhoades \& Bennet, 1990; Betrán et al., 1997). A seleção direta para aumento da produtividade sob estresse de água tem sido considerada ineficiente, tanto por causa do decréscimo da produção sob estresse de umidade, com conseqüente diminuição da herdabilidade (Bolanos, et al. 1993 b), quanto devido às dificuldades em se trabalhar em áreas que apresentam variações climáticas bastante acentuadas onde $o$ controle do ambiente é muito difícil (Santos et al. 2000). Além dessas dificuldades, poucos são os programas de melhoramento para ambientes que apresentam algum tipo de estresse, sendo que a maioria dos trabalhos nessa linha de pesquisa tem usado características morfológicas e fisiológicas de difícil medição no campo e que não se correlacionam com a produtividade (Blum, 1988). 
De acordo com Falconer (1960), o uso de características secundárias de fácil medição e com valor adaptativo alto podem aumentar a eficiência da seleção em condição de estresse. A partir da década de 80 , surgiram vários trabalhos (Edmeades \& Bolanos, 1989; Ludlow \& Muchow, 1990; Boyer, 1996) que relatavam características fenotípicas e fisiológicas, tais como precocidade, temperatura foliar, abertura e fechamento dos estômatos, senescência foliar, ajuste osmótico, entre outras, que estavam associadas com a produção, mas que não mostraram ser eficientes para a produção do milho sob estresse de umidade. Resultados apresentados por Edmeades et al. (1989) indicaram, entre vários parâmetros, que a sincronia de florescimento masculino e feminino (ASI) é uma característica de fácil medição e que está associada negativamente com a produção sob condições de estresse. Vários outros resultados apresentados por Bolanos \& Edmeades (1993 a, b) e Chapman et al. (1997) vieram confirmar que a característica ASI foi a que mais se correlacionou com a produção sob estresse de água. Resultados recentes apresentados por Betrán et al. (1997) mostram os efeitos severos do estresse de água para híbridos e linhagens e recomendam que, para se obterem performances aceitáveis de produção nos híbridos, as linhagens parentais devem apresentar sincronia entre o florescimento masculino e feminino (ASI), uma vez que as mais altas correlações foram encontradas com linhagens selecionadas sob estresse. $\mathrm{O}$ presente trabalho teve por objetivo avaliar híbridos de milho obtidos a partir de linhagens selecionadas e não selecionadas para a característica ASI, a fim de verificar suas respostas sob condições de estresse de água no período de fertilização/enchimento de grãos.

\section{Material e Métodos}

No ano agrícola de 2000, foram avaliados, em Janaúba, MG, dois experimentos, sendo um com estresse de água no período de fertilização/enchimento de grãos e um sob condições normais de irrigação. Janaúba está localizada na região norte de Minas Gerais, altitude de $516 \mathrm{~m}$, latitude $15^{\circ} 47^{\prime} \mathrm{S}$ e longitude $43^{\circ} 18^{\prime} \mathrm{W}$. Os ensaios foram conduzidos na época em que a probabilidade de chuvas é mínima (junho a setembro) e, nesse ano, não ocorreu nenhuma precipitação durante o desenvolvimento da cultura. As irrigações foram feitas utilizando o sistema de irrigação por aspersão convencional com as laterais fixas. O manejo baseou-se na evapotranspiração de referência, obtida com dados de uma estação meteorológica localizada nas proximidades e dados de coeficientes de cultivo médio para milho. As lâminas de irrigação aplicadas foram medidas em baterias de 16 coletores instalados em cada experimento. No ensaio com estresse, as irrigações foram interrompidas aos 55 dias após o plantio (dap) e reiniciadas aos 90 dap. Para avaliar o nível do estresse hídrico aplicado, monitorou-se a umidade do solo nas camadas de 0 a 20, 20 a 40 e 40 a $60 \mathrm{~cm}$ do perfil do solo, empregando-se o método gravimétrico. Os dados de umidade foram convertidos para lâmina de armazenamento de água e comparados com dados de disponibilidade de água no solo. Foram utilizados 22 tratamentos, formados por: dez híbridos não selecionados para a característica sincronia de florescimento masculino e feminino (NSASI), cinco híbridos em que todas as linhagens parentais haviam sido selecionadas $(100 \%$ ASI), cinco híbridos em que havia a participação de um parental ASI na sua formação (50\% ASI), uma testemunha comercial sem seleção para ASI (BRS 31011) e uma testemunha de reconhecida estabilidade de produção, mas sem informação sob sua formação e processo de seleção (P 3041). Em ambos os ensaios, o delineamento experimental utilizado foi em blocos ao acaso, com três repetições, e a parcela foi formada por duas fileiras de $5 \mathrm{~m}$ de 
comprimento, com densidade populacional de 55 mil plantas ha ${ }^{-1}$. Foram mensurados os seguintes parâmetros: $50 \%$ de florescimento masculino (FM), em dias, $50 \%$ de florescimento feminino (FF), em dias, sincronia de florescimento masculino e feminino (ASI), peso de grãos (PG), em kg ha ${ }^{-1}$, altura de planta (AP), em cm, e número de espigas (NE). A característica ASI foi calculada subtraindo-se o número de dias entre $50 \%$ do FF e $50 \%$ do FM. A análise estatística foi realizada para cada ambiente, sendo efetuada, posteriormente, a análise conjunta. A avaliação do desempenho dos híbridos levou em consideração dois critérios: a) a produção de grãos em ambiente sob estresse hídrico; b) o comportamento relativo nos ambientes com e sem estresse. Esse comportamento foi avaliado por um "indice de estresse (IE)", definido como:

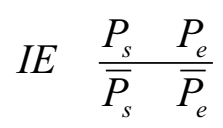

em que Ps e Pe são as produções de grãos dos híbridos nos ambientes sem e com estresse, respectivamente, e $\bar{P}_{s}$ e $\bar{P}_{e}$ são as produções médias, considerando-se todos os híbridos nos ambientes sem e com estresse, respectivamente. A partir desses dados, foi construída a Figura 1, a qual foi dividida em quadrantes, de acordo com o nível de tolerância estimado para cada híbrido. Dessa forma, quanto menor for o valor IE, maior é a tolerância do híbrido ao estresse hídrico. Valores de IE em torno de 1,0 indicam tolerância média, e altos valores estão associados à baixa tolerância ao estresse hídrico. Portanto, o híbrido de melhor desempenho é aquele que apresentar produtividade de grãos acima da média geral e índice de estresse menor que a unidade $(\mathrm{IE}<1,0)$.

\section{Resultados e Discussão}

Em trabalhos dessa natureza, a caracterização ambiental é fundamental para a validação dos

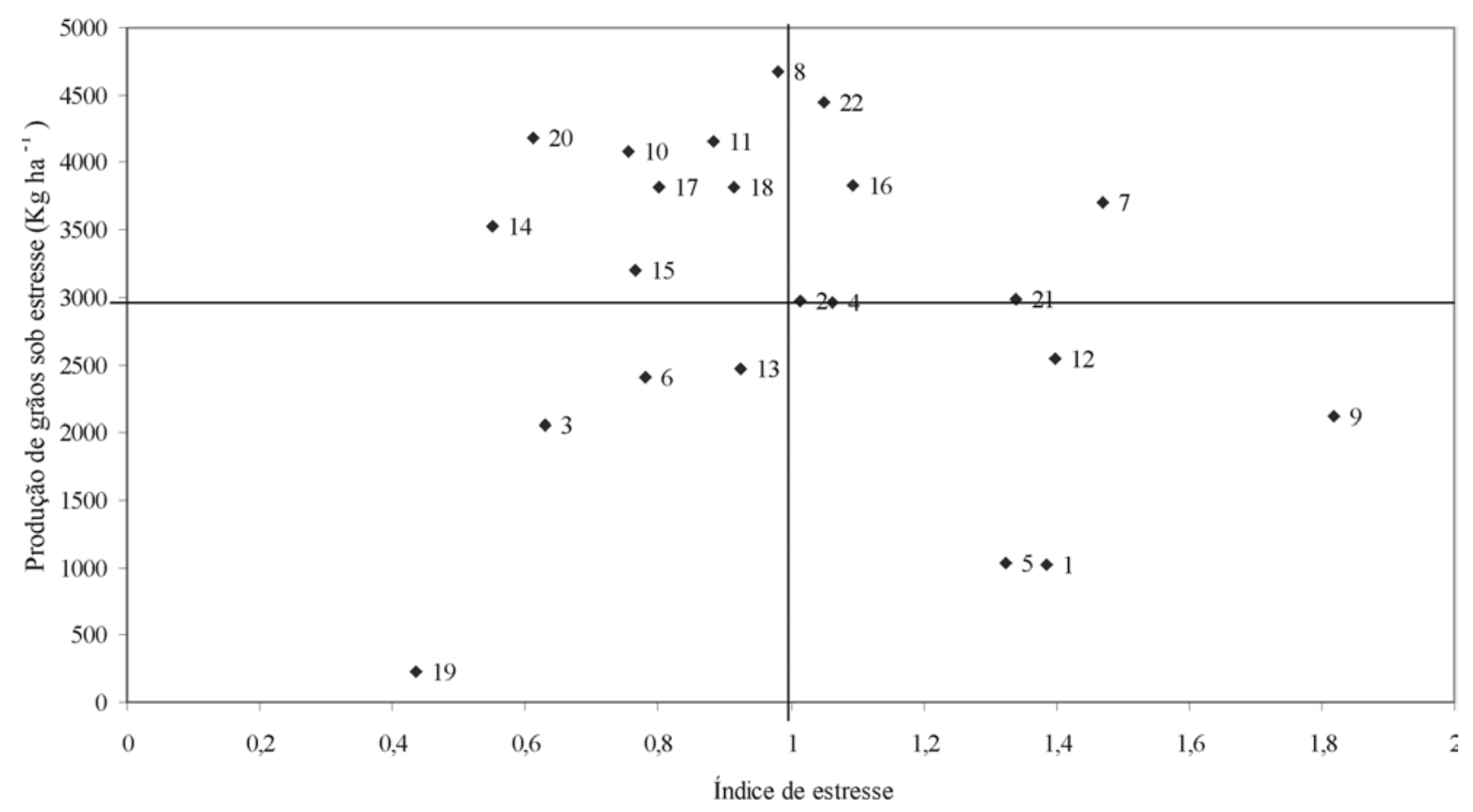

FIGURA 1. Desempenho de híbridos de milho selecionados e não selecionados para sincronia de florescimento masculino e feminino (ASI). Janaúba, MG, 2000. 
resultados obtidos. Pode-se observar, em primeiro lugar, que a duração do estresse foi considerada severa, desde que o período sem irrigação foi de mais de 35 dias (Figura 2), propiciando, dessa forma, uma avaliação para os híbridos que toleram estresse hídrico prolongado. As lâminas de irrigação aplicadas durante o ciclo foram de 454 e $574 \mathrm{~mm}$, respectivamente, para os ensaios com e sem estresse e o monitoramento da umidade do solo (Figura 3) evidenciou um estresse hídrico acentuado na camada de 0 a $20 \mathrm{~cm}$ do perfil do solo, onde, possivelmente, estava concentrada boa parte do sistema radicular da cultura. Ao se considerar a camada de 0 a $60 \mathrm{~cm}$ do perfil do solo, observou-se que, no ensaio sem estresse, a umidade do solo oscilou próximo à capacidade de campo e, no ensaio com estresse, os valores desceram abaixo de $50 \%$ da água disponível.

Após essa averiguação, efetuou-se a análise estatística para os tratamentos avaliados nos ambientes com estresse (CS) e sem estresse de umidade no florescimento/enchimento de grãos (Tabela 1), encontrando-se significância estatística $(\mathrm{P}<0,01)$ para as características peso de grãos (PG), 50\% de florescimento masculino e feminino com estresse $(50 \%$ FMCS e 50\% FFCS), número de espigas (NE) e altura de plantas (AP). Na análise conjunta, foi detectada significância estatística para ambientes, tratamentos e para a interação ambientes e tratamentos $(\mathrm{P}<0,01)$. Os valores encontrados para os coeficientes de variação experimental no ambiente com estresse foram 2 a 2,5 vezes mais altos do que no ambiente sem estresse, sendo, respectivamente, $30,25 \%$ e $13,97 \%$ para $P G, 19,63 \%$ e $8,09 \%$ para NE e $6,3 \%$ e $3,4 \%$ para AP. Em condições de estresses, valores dessa natureza ou mais elevados têm sido relatados na literatura (Chapman et al. 1997), sendo que, em condições sem estresses, esses valores podem ser considerados normais e dentro do esperado (Scapim et al. 1995).
Dias Após Plantio (dia)
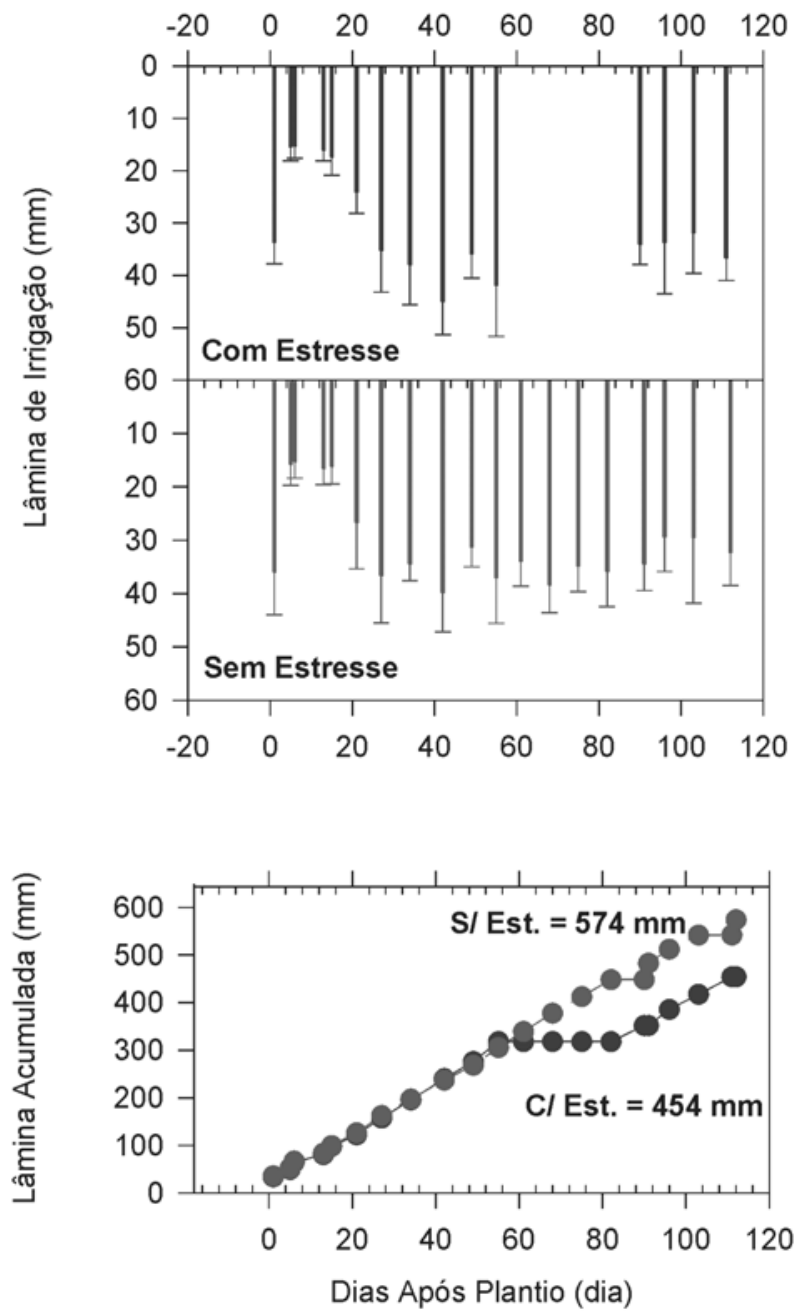

FIGURA 2. Lâminas de irrigação aplicadas e acumuladas ao longo do ciclo da cultura do milho com e sem estresse hídrico, no período do florescimento. Janaúba, MG, 2000.

$\mathrm{Na}$ Tabela 1, são mostrados os valores médios obtidos para as características estudadas, podendo-se verificar que os tratamentos foram agrupados de acordo com o percentual de participação das linhagens parentais selecionadas para a característica sincronia de florescimento masculino e feminino (ASI). Assim sendo, são mostrados os valores médios com os dez tratamentos (híbridos) não selecionados para sincronia de florescimento 


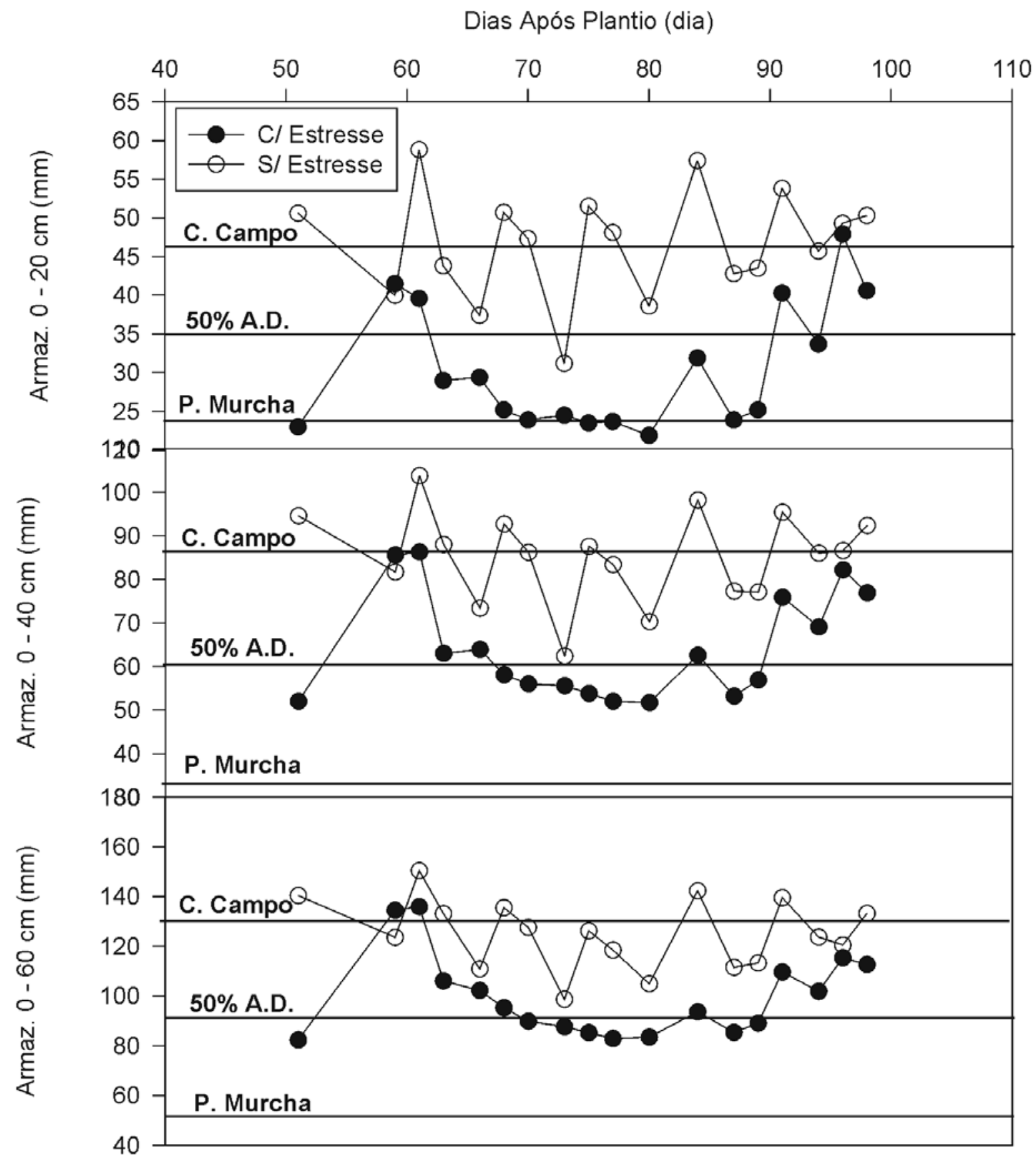

FIGURA 3. Armazenamento de água no solo ao longo do ciclo do milho com e sem estresse hídrico no florescimento. Janaúba, MG, 2000.

(NSASI), cinco tratamentos em que todas as linhagens foram selecionadas para ASI (100\% ASI) e outros cinco tratamentos em que metade dos parentais participou na combinação híbrida (50\% ASI).
Observando-se os valores médios para 50\% FMCS e $50 \%$ FFCS, nota-se que os híbridos com ASI foram mais precoces e que a amplitude de variação foi de 60 a 67 dias para o FM e de 60 a 69 


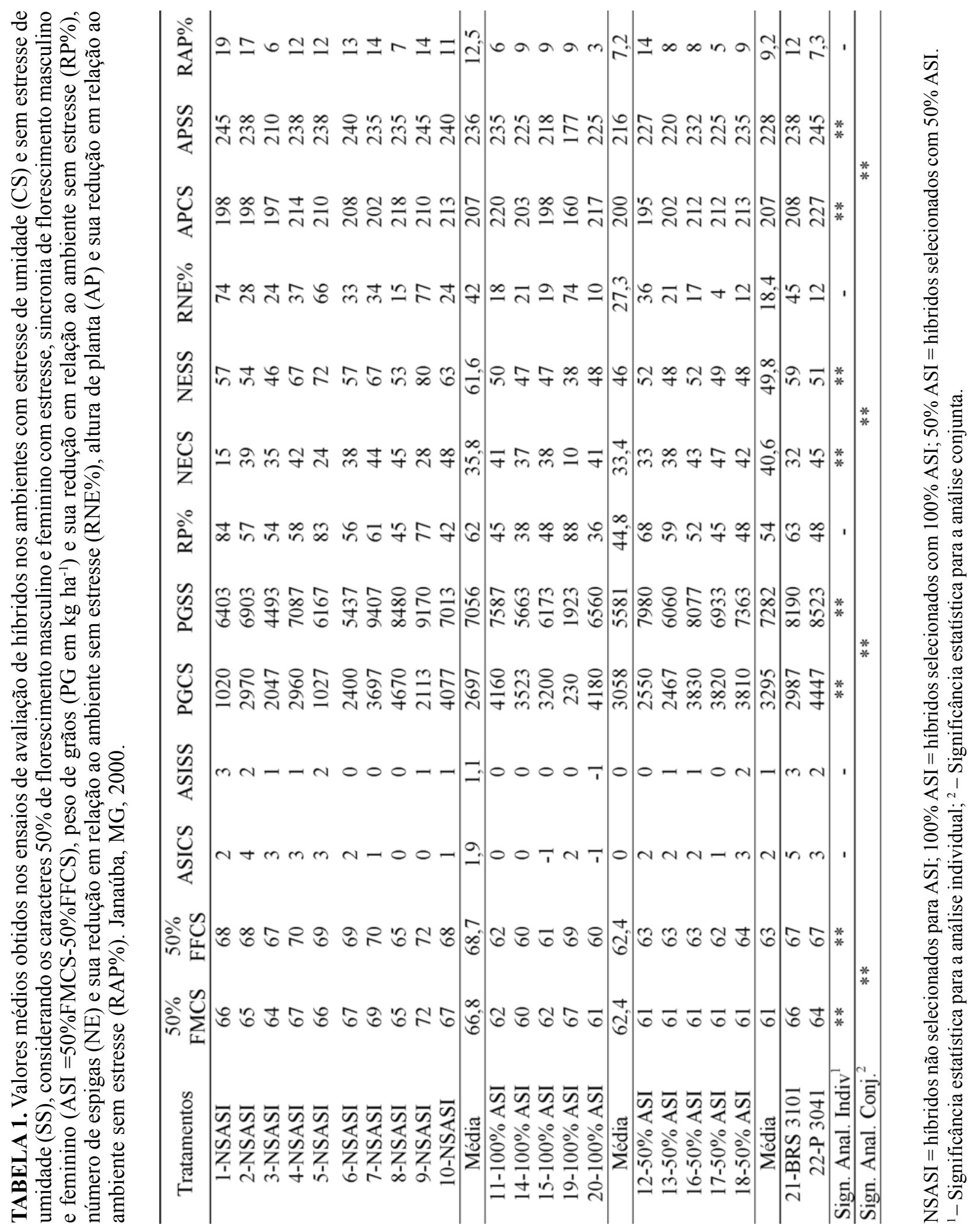

Revista Brasileira de Milho e Sorgo, v.2, n.2, p.71-81, 2003 
dias para o FF, enquanto que para os híbridos sem ASI a amplitude de variação para FMCS foi de 64 a 72 dias e de 65 a 72 dias para o FFCS. Em relação à característica ASI, pode-se observar (Tabela 1) que, de modo geral, há uma tendência em se ter protandria no ambiente com estresse; todavia, quando se observam os tratamentos com $100 \%$ ASI, percebe-se um ASI médio com valor zero e alguns tratamentos com protoginia tanto no ambiente CS quanto no ambiente SS, mostrando a eficiência da seleção para ASI. Variações de 0 a 8,2 dias no ASI sob condições de estresse têm sido relatadas na literatura e estão mais em função da relação entre a seleção das linhagens (Betrán et al., 1997). Essa característica parece conferir maior valor adaptativo ao híbrido; no entanto, isso não ficou evidenciado em termos de produtividade, sendo, talvez, parte de algum mecanismo constitutivo (Banziger et al., 2002), mas pouco se conhece sobre esses mecanismos que podem contribuir para o aumento da produção. Um exemplo que pode ser citado é o caso do tratamento 11 , uma vez que apresenta alta produção CS e SS (selecionado para ASI) e baixo valor para o índice de estresse (Figura 1). Apesar de a testemunha P 3041 (não se sabe sua origem e processo seletivo) ter apresentado boa produtividade em ambos os ambientes, pode-se averiguar, através do índice de estresse, que sentiu bem mais a falta de água durante o período do estresse. Considerando, por outro lado, que os tratamentos com ASI são híbridos originários de um mesmo grupo heterótico, fica difícil efetuar comparações ou tirar conclusões em termos de produtividade. Apesar das exceções ocorridas, pode-se observar que, sob condições de estresses, a média dos híbridos NSASI foi a mais baixa (2.697 kg ha-1) e a mais alta foi com a dos híbridos com $50 \%$ (3.295 $\left.\mathrm{kg} \mathrm{ha}^{-1}\right)$, em virtude de a média dos híbridos com $100 \%$ ASI ter sido prejudicada pelo baixo stand do tratamento 19 (Tabela 1).
Observando-se, ainda, a redução de produtividade do ambiente sem estresse em relação ao ambiente com estresse, pode-se verificar uma redução de $62 \%$ para os híbridos NSASI, com amplitude de variação de $42 \%$ a $84 \%$, enquanto que para os híbridos $100 \%$ ASI e $50 \%$ ASI essa redução foi de $44,8 \%$ e $54 \%$, respectivamente. Têm sido encontrados resultados na literatura em que são mencionadas reduções na produtividade que variando de $14 \%$ a $63 \%$ (Robins \& Domingo, 1953; Edmeades et al., 1989; Betrán et al., 1997; Santos et al., 2000; Sing-RD et al., 2000), não se mencionando, porém, como foi efetuado o controle de umidade, o estádio em que foi dado o estresse e sua duração. No presente estudo, o estresse imposto evidenciou a variabilidade para redução de produtividade (36\% a $88 \%$ ), destacando-se com menores reduções os híbridos selecionados com ASI. Considerando-se, por outro lado, o índice de estresse (Figura 1), verifica-se que apenas um (tratamento 19) dos cinco híbridos selecionados para $100 \%$ ASI não se localizou no quadrante indicativo (primeiro), que evidencia os tratamentos que sofreram menor índice de estresse de água e produtividade acima da média geral. Incluíram-se, ainda, nesse quadrante dois tratamentos selecionados para 50\% ASI (17 e 18) e apenas dois dos dez híbridos testados e não selecionados para essa característica. Estes resultados são coerentes com dados da literatura que mostram ser a seleção indireta, através do ASI, eficiente para discriminar genótipos com tolerância à seca e com boas performances de produtividade. Uma possível explicação para o fato de o tratamento 19, o único selecionado para $100 \%$ ASI, não ter sido incluído no primeiro quadrante, foi, além do baixo stand, a ocorrência de elevado número de espigas doentes e sem peso. As testemunhas, por outro lado, produziram acima da média, porém sentiram mais o efeito do estresse de água, indicando que a seleção para a condição de estresse deve ser feita no ambiente 
em que o material irá ser utilizado. Levando-se em conta que o início do estresse ocorreu aos 55 dias e o retorno da irrigação ocorreu aos 88 dias e que nesse intervalo o solo se encontrava próximo ao ponto de murcha permanente (Figuras 2 e 3), os valores médios de produtividade indicaram alguns híbridos promissores tanto no aspecto de tolerância ao estresse quanto sob condições normais de irrigação (duplo propósito). Se a característica ASI confere maior valor adaptativo e não expressa essa vantagem em termos de produtividade, algum outro mecanismo deve estar envolvido (Bazinger et al. 2002) ou deve-se buscar novas combinações híbridas com padrões heteróticos diferenciados (fato não ocorrido neste estudo) para testes de avaliação e comparações mais precisos.

Há indicações, no entanto, que parecem mostrar um outro parâmetro mais associado com a tolerância à seca que poderia, junto com a característica ASI, servir como critério de seleção. Observando-se a característica número de espigas com estresse (NECS) e sem estresse (NESS), pode-se notar que, de modo geral, os híbridos mais produtivos CS e SS apresentaram o maior número de espigas em ambas as situações (Tabela 1). No entanto, há concordância de que a seleção para tolerância à seca sem estresse de água não permite a obtenção de genótipos tolerantes (Boyer, 1996; Chapman et al., 1997; Santos et al., 2000). Percebe-se, ainda, que os híbridos selecionados para ASI apresentaram uma média menor para a redução do número de espigas (RNE\%) do que os híbridos com $0 \%$ ASI (42\%). Essa, talvez, possa ser uma das vantagens adaptativas, uma vez que o estresse intensificou a expressão de genes importantes para a reprodução e sobrevivência (Blum et al. 1992). Os resultados obtidos parecem deixar claro que a maior produtividade dos híbridos sob estresse seja devido a uma expressão de um maior número de espigas e, dessa forma, relacionados com a reprodução. Se for levado em conta que o aborto do óvulo ocorre no período de uma semana antes e duas semanas após a saída dos estilos-estigmas (Jacob \& Pearson, 1991), a formação de grãos, com conseqüente desenvolvimento de espigas, deve estar associada com a tolerância a estresse de seca. Alguns resultados da literatura mostram que o número de espigas está associado com tolerância à seca (Tollenar et al., 1997; Chapman \& Edmeades, 1999; Bazinger et al., 2002) e que a seleção para estresse de umidade conduz a mudanças morfológicas e fisiológicas para aumento da produção. Dessa forma, caracteres que conferem vantagem adaptativa, juntamente com outras características indiretas de fácil mensuração, devem ser utilizados no processo seletivo.

Para a característica altura de planta no ambiente com estresse (APCS), os valores obtidos na média dos grupos foram similares; todavia, no ambiente sem estresse (APSS) houve diferenças mais fortes na média dos grupos, que mostram, na verdade, as diferenças genéticas entre o híbridos avaliados sob condições ideais de plantio. A redução na altura da planta nos ambientes SS e CS foi de 12,5\% para os híbridos não selecionados para ASI, enquanto que para os híbridos com $100 \%$ ASI e $50 \%$ ASI as reduções foram de 7,2\% e 9,2\%, respectivamente. Resultados similares foram relatados por Santos et al. (2000) e Sain-Dass et al. (2001), os quais mostram que, sob condições de estresse, ocorreram reduções na AP, sendo que valores mais altos ou mais baixos podem ser obtidos estando em função tanto da época e duração do estresse quanto da origem genética de cada genótipo.

\section{Conclusões}

As produtividades médias mais altas dos híbridos com ASI na condição de estresse de água parecem estar mais associadas com o número de espigas do que com a característica ASI. 
Não está claro se a seleção para ASI confere produtividade mais alta ou vantagens adaptativas que são manifestadas em características correlacionadas com a produtividade.

\section{Literatura Citada}

BANZIGER, M.; EDMEADES, G.O .; LAFITTE, H.R. Physiologiccal mechanisms contributing to the increased $\mathrm{N}$ stress tolerance of tropical maize selected for drouht tolerance. Field Crop Research, Amsterdam, v.75, p.223-233, 2002.

BETRÁN, F.J.; BECK, D.; BANZIGER, M.; RIBAUT, J.M.; EDMEADES, G.O. Breeding for drought tolerance in tropical maize. In: CONFERENCE ON GENETICS, BIOTECHNOLOGY AND BREEDING OF MAIZE AND SORGHUM, 17., 1996, Thessaloniki. Proceedings... Cambridge: Royal Society of Chemistry, 1997. p.169-177. (Special Publication, 209)

BLUM, A. Plant Breeding for Stress Environments. Boca Raton: CRC Press, 1988. $223 p$.

BLUM, A.; GOLAN, G.; MAYER, J.; SINMENA B.; OBILANA, T. The comparative productivity and drought rsponse of semi-tropical hybrids and open pollinated varieties of sorghum. Journal of Agricultural Science, Cambridge, v.118,p.29-36, 1992.

BOLAÑOS, J.; EDMEADES, G. Eight cycles of selection for drought tolerance in lowland tropical maize. I. Responses in grain yield, biomass, end radiation utilization. Field Crops Research, Amsterdam, v.31, p.233-252, 1993 (a).

BOLAÑOS, J.; EDMEADES, G.O.; MARTINEZ, L. Eight cycles of selection for drought tolerance in lowland tropical maize. II. Responses in drought-adaptative physiological and morphological traits. Field Crops Research, Amsterdam, v.31, p.269-286, 1993 (b).

BOYER, J.S. Advances in drought tolerance in plants. Advances in Agronomy, New York, v. 56, p. 187-218, 1996.

CHAPMAN, S.C.; CROSSA, J.; EDMEADES, G.O. Gnotype by environment effects and selection for drought tolerance in tropical maize. II. Two mode pattern analysis of yield. Euphytica, Wagening, v.95, p. 1-9, 1997.

CHAPMAN, S. C.; EDMEADES, G. O. Selection improves drought tolerance in tropical maize populations. II. Direct and correlated responses among secondary traits. Crop Science, Madison, v.39, p.1315-1324, 1999.

EDMEADES, G. O ; BOLANOS, J.; HERNANDEZ, M.; BELLO S. Causes of silk delay in a lowland tropical maize population. Crop Science, Madison, v.33, p.1029-1035, 1993.

EDMEADES, G. O.; BOLAÑOS, J.; LAFITTE, H.R.; RAJARAM, S.; PFEIFFER, W.; FISCHER, R.A. Traditional approaches to breeding for drought in cereals. In: BAKER, F.W.G. Drought Resistance in Cereals. Wallingford: $C A B$ International, 1989. p.25-72.

FALCONER, D.A. Introduction to quantitative genetics. New York: Ronald Press, 1960. 380 p.

JACOBS, B. C.; PEARSON, C.J. Potential yield of maize determined by rates of growth and development of ears. Field Crops Research, Amsterdam, v.27, p.281-298. 1991.

JOHNSON, S.S.; GEADELMANN, J.J. Influence of water stress on grain response to recurrente selection in maize. Crop Science, Madison, v.29, p.558-565, 1989. 
LEVITT, J. Responses of plants to environmental stresses. New York: Academic Press, 1972. 697 p.

LUDLOW, M.M.; MUCHOW, R.C. 1990. A critical evaluation of traits for improving crop yields in water-limited nvironments. Advances Agronomy, New York, v. 43, 107-153, 1990.

RHOADS, F.M.; BENNETT, J.M. Corn. In: STEWART, B.A; NIELSEN, D.R. (Ed). Irrigation of agricultural crops. Madison: American Society of Agronomy, 1990. p.569-596.

ROBINS, J.S.; DOMINGO, L.E. Some effects on severe soil moisture deficits at specific stages in corn. Agronomy Journal, Madison, v.45, p.618-621, 1953.

SAIN-DASS.; PAWAN-ARORA.; MEENAKUMARI.; DHARAM-PAL.; DASS-S.;ARORAP.; PAL-D. Morphological traits determing drought tolerance in maize (Zea mays L.). Indian Journal of Agricultural Research, Haryana, v. 35, n.3, p.190-193, 2001.

SANTOS, M.X.; ANDRADE, C. L.T.; LEITE, C.E.P.; PACHECO, C.A .P.; GAMA, E.E.G.; PARENTONI, S.N.; CARVALHO, H.W.; MEIRELLES, W.F.; DURÃES, F.O. Avaliação de linhagens e híbridos de milho selecionados para sincronia de florescimento sob condições normais de irrigação e com estresse de umidade. In: REUNIÃO
TÉCNICA ANUAL DE MILHO, 45., REUNIÃO TÉCNICA ANUAL DO SORGO, 28., 2000, Pelotas. Anais... Pelotas: Embrapa Clima Temperado, 2000. p.240-252. (Embrapa Clima Temperado: Dourados, 70).

SANTOS, M.X.; LOPES, M. A; COELHO, A.M.; GUIMARÃES, P.E.O; PARENTONI, S.N.; GAMA, E.E.G.; FRANÇA, G.E. Drought and Low $\mathrm{N}$ status limiting maize production in Brazil. In: SYMPOSIUM DEVELOPING DROUGHT AND LOW N- TOLERANT MAIZE, 1996, El Batán. Proceedings... El Batán: CIMMYT, 1997. p. 2023. Edited by G. O. Edmeades, M. Bazinger, H., Mickelson, C.B. Pena-Valdivia.

SCAPIM, C. A.; CARVALHO, C.G.P.; CRUZ, C.D. Uma proposta de classificação dos coeficientes de variação para a cultura do milho. Pesquisa Agropecuária Brasileira, Brasília, v.30, n.5, p. 683-686, maio, 1995.

SINGH, R.D.; YADAV, T.P.; BHAT, J.S. Breeding strategies for drought tolerance in maize. Crop Improvement, Ludhiana, v.27, n.2, p.167-177, 2000.

TOLLENAR, M.; AGUILERA, A.; NISSANKA, S.P. Grain yield is reduced more by weed interference in al old than in a new maize hybrid. Agronomy Journal, Madison, v.89, p.239-246, 1997. 